\title{
Evaluating watershed development impacts on physical capital using household surveys and Bayesian networks
}

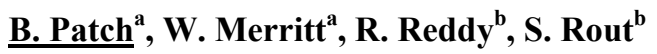 \\ ${ }^{a}$ Fenner School of Environment and Society, The Australian National University, Canberra, ACT \\ ${ }^{b}$ Livelihoods and Natural Resource Management Institute (LNRMI), Hyderabad, Andhra Pradesh, India \\ Email: brendan.patch@anu.edu.au
}

\begin{abstract}
The wellbeing of households in rural India is heavily dependent on the condition and accessibility of land and water resources. In the drier regions of India, in particular, the scarcity and deterioration of these resources has placed added pressure on vulnerable households, limiting their capacity to attain sustainable livelihoods. Livelihood assessments typically describe assets in terms of their contribution to financial, human, natural, physical and/or social capital. Physical capital assets, such as wells and livestock, not only directly provide these households with access to water and food but also create flows that increase stocks of other types of capital (e.g. financial capital). Watershed development (WSD) programs are one avenue the government of India uses to improve both livelihood opportunities for rural communities and the management of water resources and agricultural and forest lands. Traditionally, WSD has been designed and implemented at the micro-scale ( $<1500$ ha). However, concerns have been raised about the effectiveness of the WSD programs implemented at this scale as well as negative externalities on hydrologically connected villages outside of the implementation area. Reflecting these concerns, the Indian government now promotes WSD design and implementation at larger scales.
\end{abstract}

The Australian Centre for International Agricultural Research (ACIAR) is funding a project to investigate socio-economic and environmental impacts of WSD programs at the meso-scale (1500-10000 ha). An integrated modelling approach is being used to assess the beneficial and negative impacts of WSD interventions on household livelihoods and the natural resource base. Bayesian networks (BNs) are being used to develop models of drought resilience of alternative livelihood strategies across household classes and to analyse the influence of WSD on these households.

Two types of household surveys were conducted as part of the meso-scale project. One type focused on quantifying household attributes prior to and since WSD implementation. The other focused on establishing a link between a measure of household resilience and a smaller set of key household attributes. This paper shows how these surveys can be used to assess WSD effects on physical capital within a BN framework (Figure 1). The resilience survey is used to give evidence that agricultural tools are the least resilient physical capital. The full survey is used to show that WSD seems to support well ownership. This result is then connected with resilience survey results to demonstrate that this leads to increased resilience of households.

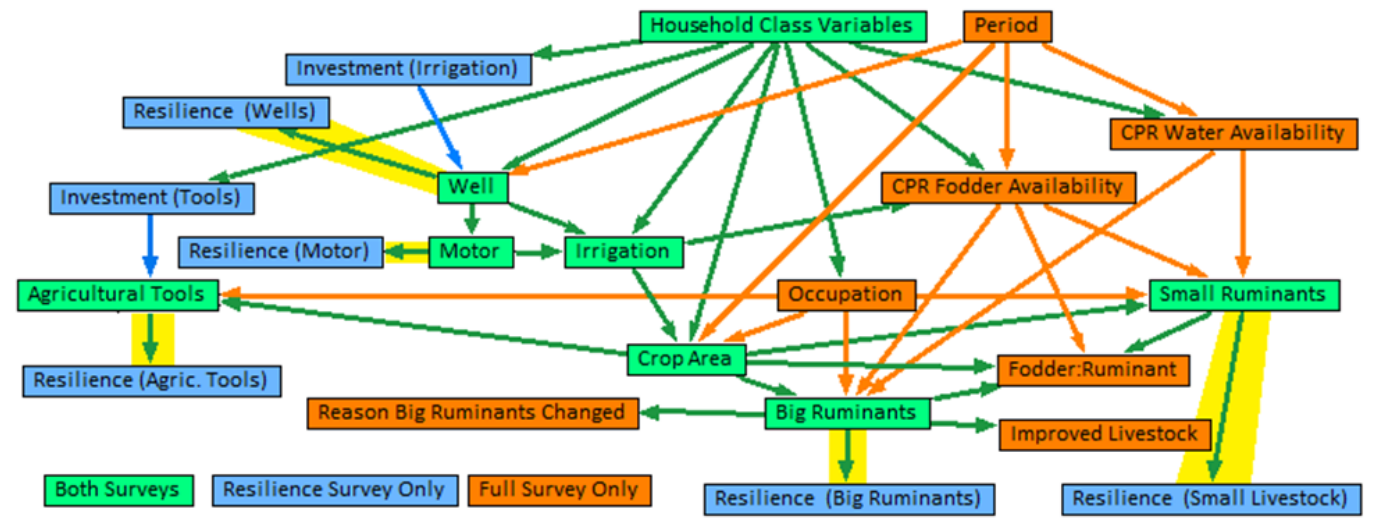

Figure 1. Influence diagram of a Bayesian network model of stocks and resilience of physical capital assets.

Keywords: $\quad$ Watershed Development (WSD), Resilience, Bayesian Networks (BNs), Household surveys 


\section{INTRODUCTION}

Many parts of rural India, particularly low rainfall regions with limited water resources, have not experienced strong economic development. Interventions in the form of improved management of natural resources or external investment to enhance natural resource utilisation may be required to alleviate the ongoing poverty in these areas. These regions may also be critical to ensuring food security in urban areas as pressures on high yield areas increase with future population growth and welfare expectations.

Watershed development (WSD) programs implement technical interventions such as soil conservation and provision of water harvesting structures to increase water availability and crop productivity and have been widely implemented in India to achieve improvements in the natural resource base and to improve livelihood opportunities for rural communities (Reddy et al., 2004). It can be difficult to quantify costs and benefits of WSD programs due to the complexity of the connected social and biophysical systems. Programs have traditionally been implemented at micro-catchment (up to 1500 hectares) or village level and some studies have been performed at this level to assess the impacts of a program (e.g. Reddy et al., 2004). However, hydrological connections between villages can result in externalities (Calder et al., 2008) which, together with the prospect of implementation efficiencies, has led the Government of India to develop guidelines that promote clusters of WSD programs at the meso-basin scale ( 5000 hectares) (Government of India, 2008).

The Australian Centre for International Agricultural Research (ACIAR) is funding a project that aims to enhance understanding of the interactions between biophysical, social and economic systems. This understanding should support the development and implementation of meso-scale WSD programs that can provide long term sustainable environmental, social, economic and institutional outcomes (Croke et al. 2012). The 'meso-scale' project is focusing on identifying the nature and distribution of both benefits and negative impacts of WSD across hydrological units and between different types of households. Bayesian networks (BNs) are one tool being used in the 'meso-scale project' to analyse household survey data and are also being used to integrate the socio-economic analyses with biophysical modelling (Merritt et al., 2011). This paper describes a BN model of physical capital populated using household survey data collected for the meso-scale project. The study design, content of the social survey data sets and BNs are outlined in the Section 2. Physical capital, in the context of the households in the study villages, is defined in Section 3 . The results section (Section 4) is used to demonstrate model relationships between stocks (quantities) of physical assets and resilience and changes in stocks and resilience after WSD implementation.

\section{APPROACH}

\subsection{Household survey data}

Households from eight villages in Andhra Pradesh were surveyed to identify the various impacts of WSD on households. Six villages were covered under WSD programs, three each from two hydrological units (analogous to subcatchments) and a control village nearby each of these hydrological units. Upstream, midstream and downstream villages were surveyed to enable analysis of the impact of WSD interventions and resource use on hydrological linkages. For more details on the survey and sampling methodology see Reddy et al. (2011).

The survey design is based on the sustainable livelihoods approach where livelihood assets are defined as a capability or potential to generate wellbeing (Sen, 1982). Livelihoods are enhanced by WSD or other interventions when household resilience against shocks (e.g. droughts) is improved without causing deterioration of natural resources (Scoones, 1998). To structure livelihood analyses, resources are often categorised based on their physical, financial, natural, human or social attributes (e.g. Masanjala, 2006). Benefits to households from holding or possessing access to a resource are measured in terms of stocks and flows. Stocks are the amount of the resource while the flows from a resource are the increases in overall stock that current levels of the resource are expected to generate over time. Often flows from a capital are seen as increases in the stock of another type of capital.

Three surveys were conducted as part of the meso-scale project. Two surveys focused on eliciting the impact of watershed development by asking each surveyed household to describe a range of household attributes prior to ('Before'), and since ('After') WSD implementation. Data on the quantity and quality of each capital indicator (e.g. savings, access to common pool resources) was collated in addition to data on consumption and production decisions and the reasons for particular decisions. The survey questions in the first full survey $(n=564)$ and second full survey $(n=570)$ are the same although the first full survey was conducted from November 2010 to April 2011 (a period of 'normal' climate conditions) and the second was conducted from December 2011 to March 2012 (a period of drought). About half of the households surveyed in the first full 
survey participated in the second, with the remainder of survey respondents being new households. The resilience survey (RS) $(n=522)$, conducted during November 2011, asked questions that would establish a link between a measure of household resilience and a small set of key household attributes. Resilience is defined as the capacity of a household to survive consecutive drought years. Except for 44 households who had moved out of their village all of the participants in the first full survey participated in the resilience survey. While the full surveys explicitly asked respondents from WSD treated villages the quantities of various assets that they possessed before and after WSD implementation, the resilience survey generally did not elicit information from prior to WSD. Using the resilience data set, the impacts of WSD are inferred by looking at the differences between treated (WSD) and control villages.

\subsection{Bayesian networks}

BNs are a type of probabilistic graphical model where variables are denoted by nodes on a directed acyclic graph (influence diagram) and dependent relationships between variables are represented by arcs linking the nodes. The probability distribution of each node given the states of its parent nodes is described by a conditional probability table (CPT). BNs have gained popularity in the field of natural resource management, particularly for complex problems requiring integration of multiple system components using data from a range of sources and in various forms (Chen and Pollino, 2012). The technique has also been demonstrated to be useful in the analysis of social survey data, in part by being open to scrutiny and analysis by end-users due to the explicit representation of relationships between variables (Ticehurst et al., 2009).

In the meso-scale project BN models are being developed for each of the five livelihood capitals. These component models are being linked to a measure of overall household resilience. Outputs from hydrology and land use models link primarily with the natural capital BN. The finalised integrated model will be used to model a range of livelihood, irrigation, climate, land use and WSD intervention scenarios. Given space constraints, this paper reports on a model developed for physical capital using data from the first full survey and the resilience survey (Figure 1). The advantage of the resilience survey is the direct relationship between the amount of a given capital and the resilience outcome variables, the links highlighted in yellow in Figure 1 (Section 4.1). The strength of the full survey is that it can be used to compare the state of households before WSD with their state since WSD (Section 4.2). It also includes additional causal or explanatory variables that can support understanding of the factors influencing the amount of different assets and reasons for any reported change since WSD. In this paper, the resilience data set (RS) is used to parameterise the resilience CPTs and the first full survey is used to parameterise the remainder of the network (Section 4.3).

\section{PHYSICAL CAPITAL}

The social surveys conducted in the study villages focus on physical capital assets that vary at the household level and which can reasonably be expected to be impacted by WSD. Given the dependence of most households on agricultural activities, physical capital is measured by the quantities of big ruminants (cows, buffaloes, young stock and drought cattle) and small ruminants (sheep and goats), agricultural tools (ploughs, sprayers, power tillers and tractors) and irrigation assets (open wells, bore wells and motors). Ruminants contribute to household livelihoods in multiple ways. Large ruminants can be used in crop production (e.g. ploughing of fields) and can be rented out to other households. Milk and meat from ruminants can be consumed by the household or sold. Ruminant ownership offers a mechanism for households to diversify savings away from currency and act as security when raising debt (Alary et al., 2011) or to sell in order to acquire other assets. Agricultural tools are used in crop production and are a source of revenue if rented out. Open wells are large holes typically up to $30 \mathrm{ft}(\sim 9 \mathrm{~m})$ deep in the study villages. Bore wells are typically deeper (up to $500 \mathrm{ft}$ or $150 \mathrm{~m}$ deep) and require a motor to pump water from a groundwater aquifer.

An influence diagram for physical capital was developed from the questions in all three surveys (Figure 1). The top level variables (inputs) are household class variables and period (before or after WSD). Household class variables specify which hydrological unit the households village belongs to, the location of the village (upstream, midstream or downstream), economic category (landless, small-marginal landholders and medium-large landholders) and social category (caste). The household class and period variables are linked through explanatory variables to a resilience variable for each physical capital indicator (e.g. Resilience (Wells)) which defines the number of droughts reported by survey respondents that would need to occur consecutively in order to exhaust stocks and flows of that capital. For example, a response of 'no drought' indicates stocks will be exhausted before the end of one drought whereas a response of 'three droughts' indicates that the stocks of the capital will last at least three consecutive drought years. 
The main explanatory variables are the stocks (amount) of each capital. These variables are the sole parent (input) variable to the resilience nodes and can be directly linked to the household class and period variables or indirectly through other explanatory variables. Motor ownership is only dependent on well ownership but both well and motor ownership affect irrigation capacity, which in turn influences crop area (irrigated and rainfed) and common pool resource fodder availability. Crop area is directly related to ruminants as it has been observed that increased irrigation capacity may result in grazing lands, including common areas, being converted to croplands (Reddy et. al., 2004). Crop area is linked to agricultural tools on the assumption that larger land holdings require more agricultural tools. Occupation is linked to household class and influences the ownership of both ruminants and tools. The variables describing investment in tools and irrigation influence stocks of these assets while access to common pool resources is linked to ruminant ownership to reflect the dependence of many households that own ruminant livestock on access to common lands for direct grazing and access to fodder. The big ruminants node is linked to variables that give reasons for changes in their ownership and whether changes have been towards breeds promoted by government agencies (e.g. for their drought tolerance).

The colour of the nodes in Figure 1 indicates which of the three surveys can be used for parameterisation of the model (full survey - orange, resilience survey - blue, either - green). The questions from the surveys corresponding to the variables in the $\mathrm{BN}$ are listed in Table 1. The next section of this paper explores the knowledge gained from each survey and their respective strengths. It also draws some implications of combining data from the different surveys on distinguishing the impacts of WSD on physical capital assets.

Table 1. Questions from the surveys used to develop a BN model of physical capital.

\begin{tabular}{|c|c|c|c|c|}
\hline Variable & First Full Survey & Resilience Survey & \multicolumn{2}{|c|}{ States in BN } \\
\hline Resilience & & $\begin{array}{l}\text { Number of consecutive droughts (0-3) } \\
\text { that the 2010-11 stocks of assets can } \\
\text { last }\end{array}$ & \multicolumn{2}{|c|}{$\begin{array}{l}\text { Not Applicable, } \\
0 \text { droughts, } 1 \text { drought, } 2 \\
\text { droughts, } 3 \text { droughts }\end{array}$} \\
\hline $\begin{array}{l}\text { Investment in } \\
\text { agricultural } \\
\text { tools or } \\
\text { irrigation assets }\end{array}$ & & $\begin{array}{l}\text { Annual average }(2008-2011) \\
\text { investment (in rupees [Rs]) by type } \\
\text { (irrigation, tractors, other implements } \\
\text { and land development) }\end{array}$ & $\begin{array}{l}\frac{\text { Tools }}{0,0-8000} \\
>8000\end{array}$ & $\begin{array}{l}\text { Irrigation } \\
\text { No, } \\
\text { Yes }\end{array}$ \\
\hline Occupation & $\begin{array}{l}\text { Major occupation of the household at time } \\
\text { of survey }\end{array}$ & & \multicolumn{2}{|c|}{ Agricultural, Labour, Other } \\
\hline Ruminants & $\begin{array}{l}\text { Quantities, value (Rs.) and types (local, } \\
\text { improved, hybrid) of cows, buffaloes, } \\
\text { cattle, young stock, sheep and goats prior } \\
\text { to and after WSD }{ }^{1}\end{array}$ & $\begin{array}{l}\text { Annual quantity of 'big ruminants' } \\
\text { and 'small ruminants' reported from } \\
2005 / 06 \text { to } 2010 / 2011^{2}\end{array}$ & $\frac{\text { Big }}{0,1 \text { to } 4,>4}$ & $\frac{\text { Small }}{\text { No, Yes }}$ \\
\hline $\begin{array}{l}\text { Reason for } \\
\text { change in } \\
\text { ruminants }\end{array}$ & $\begin{array}{l}\text { Reason for change in ownership of } \\
\text { buffaloes, young stock, cows, sheep and } \\
\text { goats since WSD }\end{array}$ & & \multicolumn{2}{|c|}{$\begin{array}{l}\text { No Change, Financial, } \\
\text { Drought, Other }\end{array}$} \\
\hline $\begin{array}{l}\text { Irrigation } \\
\text { Assets }\end{array}$ & $\begin{array}{l}\text { Quantity, type, age, depth and value of } \\
\text { wells and motors owned by household } \\
\text { prior to and since WSD }\end{array}$ & $\begin{array}{l}\text { Quantity of motors and quantity of } \\
\text { wells owned by household reported } \\
\text { for the years } 2005 / 06 \text { to } 2010 / 2011^{2}\end{array}$ & $\frac{\text { Motor }}{\text { No, Yes }}$ & $\frac{\text { Well }}{\text { No, Yes }}$ \\
\hline Crop area & $\begin{array}{l}\text { Area of land (owned +leased in - leased } \\
\text { out) occupied by primary household crop } \\
\text { prior to and since WSD }\end{array}$ & $\begin{array}{l}\text { Area of land (owned) occupied by } \\
\text { primary household crop over 2010- } \\
2011^{2}\end{array}$ & \multicolumn{2}{|c|}{$0,0-2.5,2.5-5,5-7.5,>7.5$} \\
\hline $\begin{array}{l}\text { Fodder } \\
\text { availability on } \\
\text { common pool } \\
\text { resource land }\end{array}$ & $\begin{array}{l}\text { Value of fodder and time spent acquiring } \\
\text { fodder from common pool resources by } \\
\text { type (forest, open, collection) prior to and } \\
\text { since WSD }\end{array}$ & $\begin{array}{l}\text { Quantity and value of fodder acquired } \\
\text { from common pool resource forests } \\
\text { over 2010-11 or value of benefits } \\
\text { from these lands and area of access } \\
\text { reported for the years } 2005 / 06 \text { to } \\
2010 / 2011^{2}\end{array}$ & \multicolumn{2}{|c|}{0 Rs./hr, $>0$ Rs. $/ \mathrm{hr}$} \\
\hline $\begin{array}{l}\text { Ruminant water } \\
\text { availability on } \\
\text { common pool } \\
\text { resource land }\end{array}$ & $\begin{array}{l}\text { Value of water and time spent acquiring } \\
\text { water from streams prior to and since } \\
\text { WSD for the purposes of livestock }\end{array}$ & $\begin{array}{l}\text { Adequacy of water overall for all } \\
\text { purposes from all sources (more than } \\
\text { adequate, adequate, less than } \\
\text { adequate) reported for the years } \\
2005 / 06 \text { to } 2010 / 2011^{2}\end{array}$ & $\begin{array}{l}\text { First Full } \\
\text { Survey } \\
0 \mathrm{Rs} . / \mathrm{hr}, 0- \\
3 \mathrm{Rs} . / \mathrm{hr},>3 \\
\text { Rs./hr }\end{array}$ & $\begin{array}{l}\text { Resilience } \\
\text { Survey } \\
>\text { adequate, } \\
\text { adequate, }< \\
\text { adequate }\end{array}$ \\
\hline $\begin{array}{l}\text { Fodder } \\
\text { consumption by } \\
\text { ruminants }\end{array}$ & $\begin{array}{l}\text { Quantity of fodder consumption by source } \\
\text { (own, purchased, obtained from common } \\
\text { lands) prior to and since WSD }\end{array}$ & & \multicolumn{2}{|c|}{$\begin{array}{l}\text { Not Applicable, } 0-500 \\
500-1500,>1500\end{array}$} \\
\hline
\end{tabular}




\section{RESULTS}

\subsection{Household stocks and resilience for physical capital assets}

The relationship between stocks of each capital asset owned by households and the resilience of these stocks is shown in Figure 2. Each bar in the graphs show the distribution of the resilience of these stocks across four states $(0,1,2$ or 3 droughts) in the BN resilience variables, conditional on the ownership level specified on the horizontal axis. For example, the blue rectangle on the top left of Figure 2a shows a 0.18 probability that a household's stock of big ruminants will last at least three droughts if the household owns one or two big ruminants. For households that own more than four large ruminants the probability that their stock will last at least 3 consecutive drought years increases to 0.55 . The decreasing size of the red and yellow rectangles from left to right for big ruminants (Figure 2a), small ruminants (Figure 2b) and agricultural tools (Figure 2c) indicates that, as expected, the probability a household reports low drought resilience (0 Drought and 1 Drought) decreases as stocks of a resource increase.
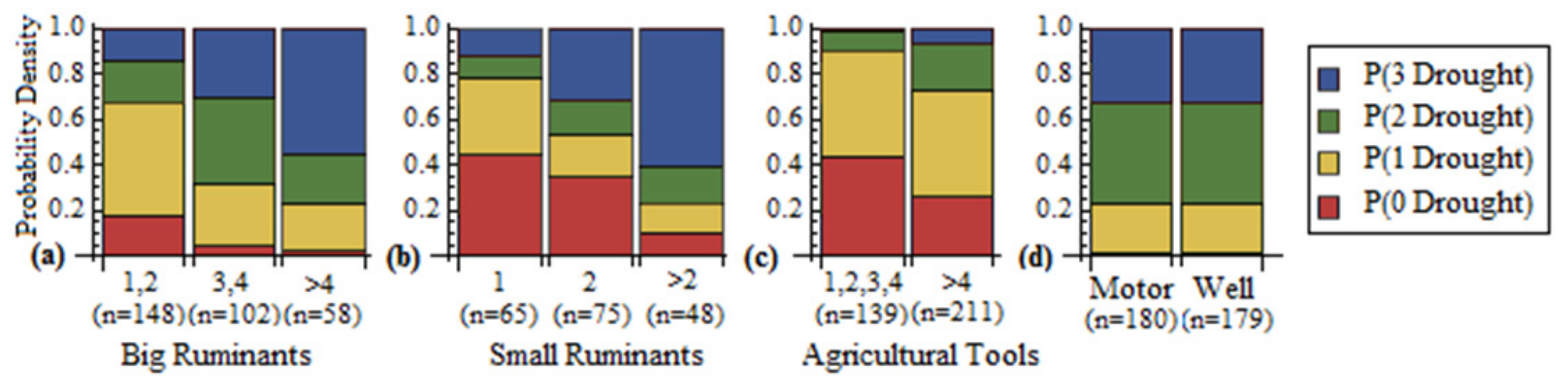

Figure 2. Distribution of resilience for each capital conditional on ownership level: (a) big ruminants (b) small ruminants (c) agricultural tools and (d) motors and wells.

Less than $20 \%$ of the survey respondents who owned one small ruminant stated that their household stocks would last at least 3 consecutive drought years; most reported that their stocks would last one or fewer drought years (Figure 2b). This is somewhat counterintuitive as small ruminants can survive on meagre resources and so household stocks could be expected to survive three or more consecutive droughts. However, households with larger flocks of small ruminants $(>2)$ tend to report a higher resilience with a 0.77 probability of being in the 2 or 3 drought survival categories. These results may indicate households with small numbers of sheep or goats may be more likely sell their stocks of small ruminants as drought conditions commence to maintain or access other capital resources.

Household stocks of agricultural tools are less resilient than stocks of big ruminants with a 0.73 probability of households reporting stocks would last one or fewer drought years when households own four or more tools (Figure 2c). This may suggest that, for most households, agricultural tools are among the first assets to be exhausted (i.e. sold) under drought conditions.

In Figure $2 \mathrm{~d}$ the resilience distribution is conditioned on a household reporting ownership of one or more of the asset. Resilience of wells is similarly distributed to resilience of motors, (Figure 2d), indicating that these irrigation assets are co-dependent (i.e. bore wells, which are the most common well type, require motors to pump water for irrigation). Both irrigation assets have a resilience of at least one drought as indicated by the negligible probability for 0 droughts.

\subsection{Determinants of household stocks of physical capital assets}

In Figure 1, the household and period variables are connected to stocks of the physical capital assets to enable the representation of WSD impacts across geographic (hydrological unit, location), social and economic categories. By using the first full survey to parameterise these input variables and household well stocks, the probability that a household owns a functioning well prior to and after WSD conditional on hydrological unit and stream location is shown in Figure 3. The Before-After-Control-Intervention (BACI) design of the first full survey clearly shows for both hydrological units that, subject to hydrogeological suitability, increased landholder access to groundwater resources has occurred since WSD. Increases occurred across all treated villages after WSD except in the midstream village in Anantapur Kurnool. Increases in Prakasam were greater than for Anantapur Kurnool. The largest increase in Anantapur Kurnool was 0.06 in the upstream location whereas the upstream location in Prakasam experienced the smallest increase of 0.08. The largest increase in Prakasam was 0.2 for the midstream households. Midstream and upstream villages in Anantapur Kurnool are not in locations suitable for expansion of groundwater irrigation 
and so there is little increase in bore well ownership. Prakasam is hydrogeologically more suited to bore well establishment. For this hydrological unit well ownership in the midstream village increased after WSD to levels which are similar to the downstream village.
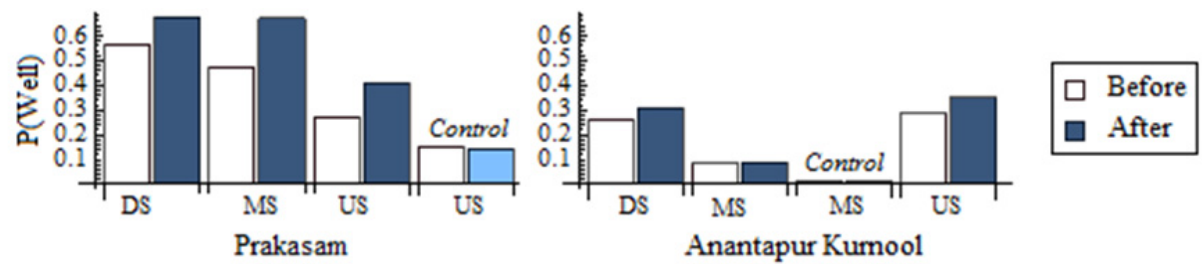

Figure 3. Probability of functional well ownership by stream location (DS - downstream, MS - midstream, US - upstream) and period (Before, After) in each hydrological unit.

\subsection{Impacts of WSD on resilience of physical capital stocks}

Where there is reasonable agreement between the quantities of household stocks reported in both surveys we consider it valid to parameterise the household, period and stock variables using the first full survey and to develop relationships between stocks and resilience using the resilience survey. There is a high level of agreement between the two surveys for well ownership and reasonable agreement for big ruminants. The resilience of wells and big ruminants before and after WSD is shown in Figure $4 \mathrm{a}$ and $4 \mathrm{~b}$, respectively. Households in the Prakasam control village have limited access and therefore reliance on wells compared to those villages that received WSD (Figure 4a). After WSD, households within the treated areas in Prakasam experienced increases in reliance (i.e. less N/A) on wells and greater resilience of their well stocks under consecutive droughts. The probability of a household in these areas reporting that their wells would last at least one drought increased from 0.45 before WSD to 0.61 after WSD. Control and treatment villages in Prakasam are very similar in terms of ownership of big ruminants. This results in a highly similar distribution of resilience for this asset (Figure 4b). Similarly, the difference between periods for ownership and resilience of this asset is less than $1 \%$. This suggests that WSD had a negligible effect on the ownership of big ruminants or the drought resilience that households obtain from owning big ruminants.
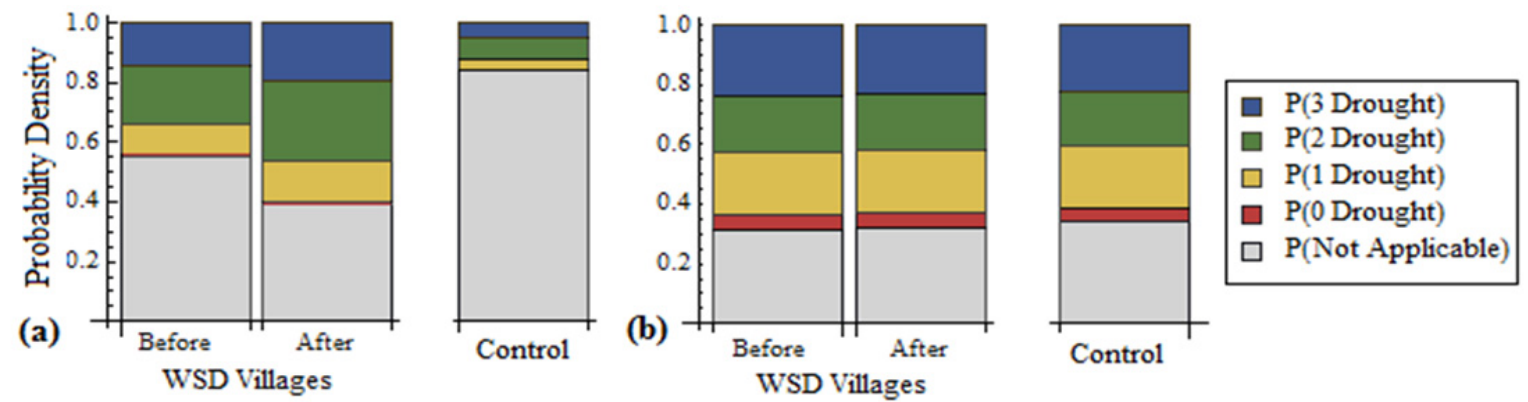

Figure 4. Resilience distribution of wells (panel a) and big ruminants (panel b) conditional on period compared to control village for households with land in Prakasam.

\section{DISCUSSIONS AND CONCLUSIONS}

The meso-scale project aims to investigate the impacts of WSD, and how they vary across the landscape and between households, on both land and water resources and the level and resilience of household capital assets. BNs are being used in the project to integrate livelihood indicators of rural households and their resilience to drought to their access and use of land and water resources. Three household surveys were conducted for the meso-scale project in order to elicit the level of various assets that enhance a household's capacity to achieve a desired livelihood and resilience to consecutive droughts. Questions were structured using the sustainable livelihoods approach to capture impacts of WSD on indicators of financial, human, natural, physical and social capital. This paper reported on the development of a BN model of physical capital. Models are also in development for the other capitals and overall household resilience.

As expected, the resilience of physical assets increases with increased quantities of stocks owned by households. A sizeable proportion of households reported low resilience (one or fewer drought years) for agricultural tools, regardless of the number of tools they owned, and when low numbers of small or large ruminants were owned by the household. Although no impact of WSD on big ruminant ownership was 
detected, WSD has led to increased well ownership in both hydrological units. However, expansion is constrained in the Anantapur Kurnool by the areas hydrogeology. This result highlights the importance of undertaking hydrogeological characterisations during the design phase of future WSD projects where access and utilisation of groundwater resources is an intended outcome. The increased ownership of wells across the WSD villages in Prakasam has likely enhanced the strength of household physical capital and resilience to consecutive droughts. The implications of increased access to groundwater on other capital assets (e.g. income, savings and debts) and the available water resource will be investigated by linking the physical capital BN with models of financial and natural capital within an integrated model.

The aim of the integrated model is to relate biophysical parameters such as groundwater storage capacity and crop productivity to overall household resilience through the indicators of capital assets. This will allow analysis of the potential impacts of climate or land and water use scenarios. The social and biophysical dimensions of integrated models and BNs, such as those being developed for the meso-scale project, are highly complex. There is often a trade-off between representing causal relationships and developing a model which has the minimum level of complexity required to provide robust, plausible and reliable performance. This issue is compounded by the low levels of socio-economic data usually available to parameterise models targeted at water planning and management. Even with a sample size of over 500 respondents, there is insufficient data to learn relationships in the BNs across all combinations of the household class variables (hydrological unit, location, economic category and social category). Future work will focus on estimating the error in the parameters of the $\mathrm{BN}$ models developed in this paper.

\section{ACKNOWLEDGMENTS}

This research is funded by the Australian Centre for International Agricultural Research.

\section{REFERENCES}

Alary, V., C. Corniaux, and D. Gautier, (2011). Livestock's Contribution to Poverty Alleviation: How to Measure It? World Development, 39, 1638-1648.

Calder, I., A. Gosain, M.S.R.M. Rao, C. Batchelor, M. Snehalatha and E. Bishop, (2008). Watershed development in India. 1. Biophysical and societal impacts. Environment, Development and Sustainability, 10:537-557.

Chen, S.H and C.A. Pollino, (2012). Good practice in Bayesian network modelling. Environmental Modelling and Software, 37, 134-145.

Croke, B., N. Herron, P. Pavelic, S. Ahmed, V. R. Reddy, R. Ranjan, G. Syme, M. Samad and K. V. Rao., (2012). Impacts of meso-scale Watershed Development in Andhra Pradesh (India) and their implications for designing and implementing improved WSD policies and programs. Water Practice \& Technology, 7 No 1

Government of India (2011). Common guidelines for watershed development projects, 59 pp. (http://dolr.nic.in/dolr/downloads/pdfs/Common\%20Guidelines\%20for\%20WDP\%202008\%20Revised\%2 0Edition\%202011.pdf; Accessed 30 July 2013).

Masanjala, W. (2007). The poverty-HIV/AIDS nexus in Africa: A livelihood approach. Social Science \& Medicine 64, 1032-1041

Merritt, W.S., V.R. Reddy, K.V. Rao, P. Pavelic, S. Ahmed, R. Ranjan, B.F.W. Croke, and G.J. Syme, (2011). Integrated modelling for understanding watershed development impacts on social and biophysical systems, Paper presented at MODSIM 2011 Congress, Perth, 12-16 December.

Reddy, V.R, M.G. Reddy, S. Galab, J. Soussan and O. Springate-Baginski, (2004). Participatory Watershed Development in India: Can it Sustain Rural Livelihoods? Development and Change, 35, 297-326.

Reddy, V., R, G. Syme, R. Ranjan, P. Pavelic, M.S. Reddy, S. Rout and N. Acharya (2011), Scale Issues in Meso-Watershed Development: Farmers' Perceptions on Designing and Implementing the Common Guidelines LNRMI Working Paper No. 2 Livelihoods and Natural Resources Management, Institute, Hyderabad, 39 pp. (Available http://www.Inrmi.ac.in/pdf/lnrmi\%20WP\%202\%201-10-11_Revised.pdf; Accessed 30 July 2013)

Scoones, I., (1998). Sustainable rural livelihoods: a framework for analysis. Working Paper 72. Brighton, UK: Institute of Development Studies.

Sen, A. (1981). Poverty and Famines: An Essay on Entitlement and Deprivation. Oxford University Press, Oxford

Ticehurst, J.L., A. Curtis, and W.S. Merritt, (2011). Using Bayesian Networks to complement conventional analyses to explore landholder management of native vegetation. Environmental Modelling and Software, $26,52-65$. 